\title{
A Corrente do Brasil ao Largo da Costa Leste Brasileira
}

\author{
(The Brazil Current off the Eastern Brazilian Coast)
}

\author{
Ilson Carlos Almeida da Silveira; André Campos Kersten Schmidt; Edmo José Dias Campos; \\ Sueli Susana de Godoi \& Yoshimine Ikeda
}

Instituto Oceanográfico da Universidade de São Paulo

(Caixa Postal 66149, 05315-970 São Paulo, SP, Brasil)

- Abstract: There is relatively few and sparse information in the literature about the Brazil Current, the boundary current that closes the western border of the South Atlantic Subtropical Gyre. In this article, we present a review of the currently-available literature to give a coherent overview on the kinematic and dynamical aspects of the Brazil Current along the Eastern Brazilian eoast. We discuss the current structure in terms of its water mass composition and its vertical extension. We compile the available information on the Brazil Current velocity structure and volume transport along the shelf and shelf break from $9^{\circ} \mathrm{S}$ to $31^{\circ} \mathrm{S}$. We also address the Brazil Current meandering and eddy formation, and their possible role in promoting shelf-break upwelling off the Southeast Brazilian coast.

- Resumo: Existe limitada e esparsa informação na literatura sobre a Corrente do Brasil, a corrente de contorno que fecha o Giro Subtropical do Atlântico Sul em sua borda oeste. Neste artigo, compilamos as informações atualmente disponíveis na literatura para fornecer uma visão dos aspectos cinemáticos e dinâmicos desta corrente, enquanto flui ao largo do Leste Brasileiro. Discutimos sua composição em termos de massas de água e de sua extensão vertical em diversas latitudes. Também apresentamos levantamento atualizado sobre aspectos cinemáticos desta corrente, tanto em termos de velocidades observadas e geostróficas como de transportes de volume. Informações sobre o meandramento e formação de vórtices na Corrente do Brasil, ao largo da costa Sudeste, e seu provável papel na penetração da Água Central do Atlântico Sul, na quebra da plataforma continental, igualmente são abordados.

- Descriptors: Brazil current, Water masses, Volume transport, Meạdering, Eddy formation.

- Descritores: Corrente do Brasil, Massas de Água, Transporte de volume, Meandros, Vórtices.

Introdução

A Corrente do Brasil (CB) é a corrente de contorno oeste associada ao Giro Subtropical do Atlântico Sul (Fig. 1). Origina-øe ao sul de $10^{\circ} \mathrm{S}$, na região onde o ramo mais ao sul da Corrente Sul Equatorial (CSE) se bifurca formando também a Corrente do Norte do Brasil (CNB) (Stramma, 1991; Silveira et al., 1994). A CB então flui para sul, bordejando o continente sul-americano até a região da Convergência Subtropical (33-38 $\mathrm{S}$ ), onde conflui com a Corrente das Malvinas e se separa da costa.

$\overline{\text { Contr. } n^{\circ} 837}$ do Inst, oceanogr. da Usp.
As correntes de contorno oeste são caracterizadas por fluxos intensos, estreitos e bem definidos fluindo ao largo de margens continentais. Entretanto, a CB é descrita na literatura como uma corrente fraca relativamente à sua análoga no Atlântico Norte, a Corrente do Golfo (CG). As correntes de contorno oeste podem ser pensadas como fluxos de retorno do transporte de Sverdrup. Este último pode ser estimado pelos campos de tensão de cisalhamento do vento em larga escala. Entretanto, não há aparente diferença entre os campos de ventos dos dois hemisférios, que justifique tais diferenças entre CG e CB por tal argmento teórico (Zemba, 1991). 


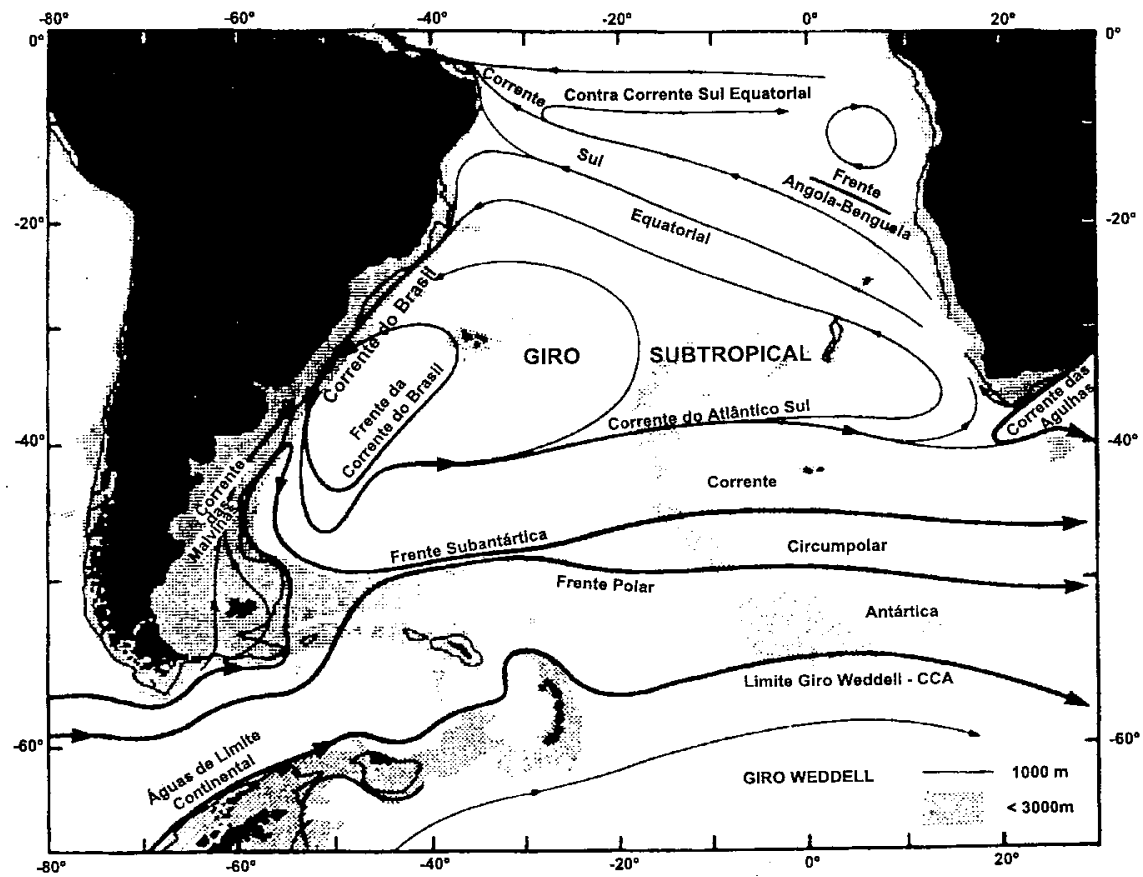

Fig. 1. Representação esquemática do Giro Subtropical do Atlântico Sul. De acordo com Peterson \& Stramma (1991).

Uma tentativa de explicação pioneira para tal diferença partiu de Stommel (1965). Separando a circulação oceânica em componentes "gerada pelo vento" e termohalina, Stommel (op.cit.) creditou a diferença entre $\mathbf{C B}$ e $\mathbf{C G}$ à possibilidade da componente termohalina ter sentido oposto daquela gerada pelo vento no Atlântico Sul (Fig. 2). No caso da CG, as componentes se somariam.

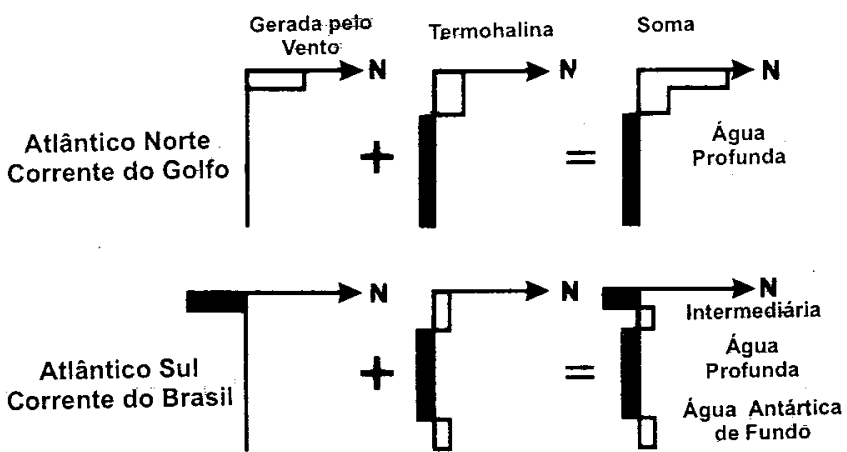

Fig. 2. Representação esquemática da hipotése de Stommel para explicar a fraca intensidade relativa da Corrente do Brasil (painel inferior) comparativamente à Corrente do Golfo (painel superior). De acordo com Stommel (1965).

Passados mais de trinta anos, a hipótese de Stommel ainda não foi contestada, embora estudos observacionais mais recentes tenham sugerido que o padrão de circulação, associado às massas de água intermediárias e profundas, seja bem mais complexo do que se supunha anteriormente. Em particular, ao largo do Sudeste e Sul brasileiro, devido às células de recirculação dessas massas, é possível que haja um fluxo contínuo ao longo dos primeiros três quilômetros de coluna d'água.

$\mathrm{Na}$ Seção 2 desse artigo, descrevem-se as massas de água na região da CB e a extensão vertical desta corrente ao largo do leste brasileiro. Na Seção 3, resumem-se aspectos cinemáticos da CB. Na Seção 4, comentam-se os meandros e vórtices da $\mathbf{C B}$ na Bacia de Santos.

\section{Massas de água e extensão vertical da Corrente do Brasil}

A região da CB é formada pelo empilhamento das massas de água características do Atlântico Sul (Fig. 3). Nos primeiros três quilômetros de coluna d'água encontram-se a Água Tropical (AT), Água Central do Atlântico Sul (ACAS), Água Intermediária Antártica (AIA), Água Circumpolar Superior (ACS) e Água Profunda do Atlântico Norte (APAN).

A AT foi descrita por Emilson (1961) como parte da massa de água quente e salina que ocupa a superficie do Atlântico Sul Tropical, a qual é transportada para o sul pela CB. Essa água de superficie é formada como conseqüência da intensa radiação e excesso de evaporação em relação à 
precipitação, característicos do Atlântico Tropical. Em seu trajeto para o sul, mistura-se com águas de origem costeira mais frias e de baixa salinidade. $O$ resultado é que a $\mathbf{A T}$ é caracterizada por temperaturas maiores que $20^{\circ} \mathrm{C}$ e salinidades acima de 36 ups, ao largo do Sudeste brasileiro.

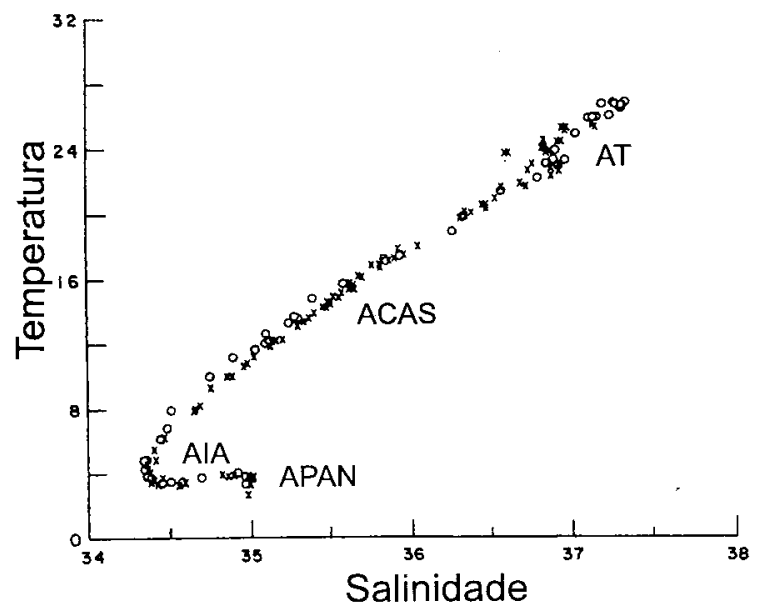

Fig. 3. Diagrama T-S espalhado de radiais oceanográficas em $19^{\circ} \mathrm{S}$ (círculos) e ao largo de Cabo Frio (cruzes). De acordo com Evans et al. (1983).

A ACAS é encontrada fluindo na região da picnoclina, e com temperaturas maiores que $6^{\circ} \mathrm{C}$ e menores que $20^{\circ} \mathrm{C}$, e salinidades entre 34,6 e 36 ups. Mais precisamente, Miranda (1985) sugere $20^{\circ} \mathrm{C}$ e 36,20 ups como índice termohalino da ACAS no Sudeste brasileiro. Sverdrup et al. (1942) mencionam que a ACAS é formada por afundamento das águas na região da Convergência Subtropical, e subseqüente espalhamento ao longo da superficie de densidade adequada a seu ajustamento hidrostático. $O$ padrão de fluxo da ACAS, no entanto, não é um simples movimento para norte em nível picnoclínico em toda bacia do Oceano Atlântico Sul. A ACAS entra como parte do Giro Subtropical, circula com as Correntes do Atlântico Sul e Benguela, e atinge a costa da América do Sul transportada pela Corrente Sul Equatorial. Como nas correntes em superficie há bifurcação e parte da ACAS flui rumo ao equador, enquanto outra porção toma a direção sul. A localização exata da separação do fluxo da ACAS é incerta. No entanto, parece existir consenso na literatura de que ao sul do Cabo de São Tomé $\left(22^{\circ} \mathrm{S}\right)$, a ACAS flui para o sul ao largo da costa brasileira. As primeiras evidências de tal padrão foram apresentadas por Wüst (1935) e Defant (1941).

Wüst (op. cit.) aplicou seu "Método do núcleo", o qual consiste em determinar os valores extremos de salinidade ou temperatura na região de formação da massa de água, e assim acompanhar o espalhamento e mistura desta através de um máximo secundário, com dados hidrográficos da região. Por seus resultados, este autor considerou a CB contida na troposfera oceânica (formada por AT e ACAS) e com espessura de $400-700 \mathrm{~m}$ ao largo do Sudeste-Sul brasileiro. Defant (1941) aplicando o cálculo geostrófico corroborou as considerações de Wüst (1935). Em apoio às referências clássicas citadas, análises mais recentes como aquelas realizadas por Tsuchya (1986), Reid (1989) e Stramma \& England (1999) parecem também confirmar o movimento da ACAS na direção do polo Sul em latitudes abaixo de $20^{\circ} \mathrm{S}$, ao largo da costa Sudeste brasileira (Fig. 4).

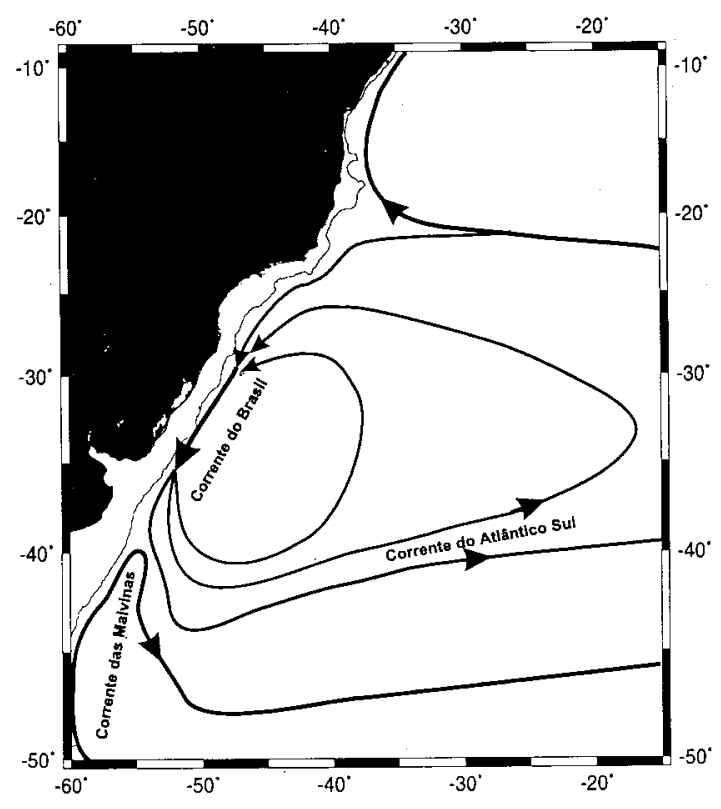

Fig. 4. Representação esquemática da circulação no Oceano Atlântico Sudoeste ao nível de $250 \mathrm{~m}$. Baseada em Reid (1989) e Stramma \& England (1999).

Se existe um aparente consenso a respeito dos movimentos das AT e ACAS, ao largo da parte mais setentrional da costa brasileira, o mesmo não pode ser dito sobre os movimentos da AIA, em nível subpicnoclínico. Segundo Sverdrup et al. (1942) os limites termohalinos da AIA são $3^{\circ}-6^{\circ} \mathrm{C}$ para temperatura e $34,2-34,6$ ups para salinidade, e demarcada pelo mínimo de salinidade no diagrama T-S (Fig. 3). A imagem clássica, sugerida pelos pioneiros estudos de Wüst (1935) e Defant (1941), exibe a AIA sendo formada na Convergência Subantártica, "espalhando-se" em níveis intermediários e fluindo para o norte. Outros autores no entanto, como Taft (1963), Buscaglia (1971), Reid et al. (1977) e Gordon \& Greengrove (1986) apoiam a idéia de que a maior parte da AIA flui para leste na Confluência Brasil-Malvinas $\left(\approx 38^{\circ} \mathrm{S}\right)$, como parte de uma recirculação mais profunda associada ao Giro Subtropical. Esta água fluiria então anticiclonicamente, e parte uniria-se novamente ao contorno oeste, em torno de Cabo Frio $\left(23^{\circ} \mathrm{S}\right)$, em um padrão semelhante ao da ACAS. As análises de Reid 
(1989), Zemba (1991), Suga \& Talley (1995) e Boebel et al. (1997) confirmam que no limite sul da Bacia de Santos $\left(\approx 30^{\circ} \mathrm{S}\right)$, a AIA flui para o sul ao largo da costa brasileira. Os resultados de Reid (1989) são ambíguos em relação à direção da AIA, entre o Cabo de São Tomé $\left(22^{\circ} \mathrm{S}\right)$ e o Cabo de Santa Marta Grande $\left(27^{\circ} \mathrm{S}\right)$, provavelmente conseqüência da resolução de sua análise de escala hemisférica.

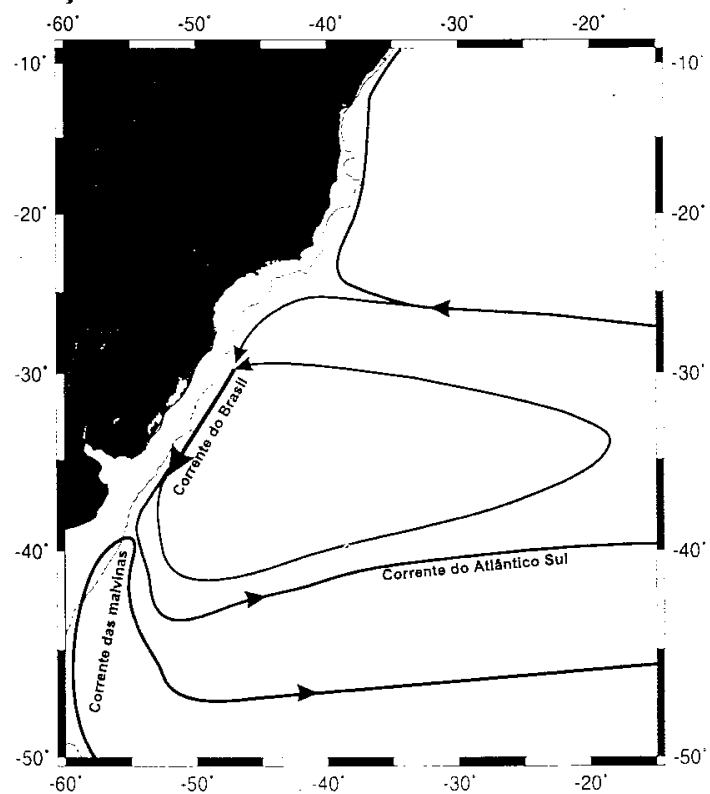

Fig. 5. Representação esquemática da circulação no Oceano Atlântico Sudoeste ao nivel de $800 \mathrm{~m}$. Baseada em Reid (1989), Stramma \& England (1999) e Boebel et al. (1999).

Piola \& Gordon (1989) sugerem um padrão híbrido entre a visão clássica e a mais moderna, onde seria possível que um ramo menor da AIA fosse transportado para o norte ao longo do contorno oeste, enquanto um ramo maior fluiria como parte profunda do Giro Subtropical.

Recentes observações diretas, entretanto, parecem ter resolvido a polêmica. A análise de dados correntométricos conduzida por Castro \& Moreira $(1994)^{*} \mathrm{e}$, posteriormente, Moreira (1997), à latitude da cidade de Santos $\left(23^{\circ} \mathrm{S}\right)$, indica que o fluxo em profundidades de $700 \mathrm{~m}$ foi para norte (mais precisamente nordeste, devido a orientação da costa) no decorrer do verão de 1993. Já os resultados dos fundeios do "World Ocean Circulation Experiment WOCE" nas latitudes de $20^{\circ} \mathrm{S}, 24^{\circ} \mathrm{S}$ e $28^{\circ} \mathrm{S}$, descritos por Müller et al. (1998), corroboram os de Moreira (1997), e são coerentes com os padrões de fluxo propostos pelos estudos hidrográficos anteriores de Reid (1989) e Suga \& Talley (1995). Müller et al. (1998) concluem que a AIA move-se em direção ao

(*) Castro Filho, B. M. \& Moreira, J. R. G. B. 1994. Current measurements in the Santos Continental Shelf. In: Southwestem Atlantic Physical Oceanography Workshop, Universidade de São Paulo, São Paulo,Brasil, p. 48. equador ao norte de $25^{\circ} \mathrm{S}$, enquanto apresenta-se como uma corrente de contorno oeste bem definida, em níveis subpicnoclínicos, fluindo para o sul em $28^{\circ} \mathrm{S}$. Assim, os estudos de Müller et al. (1998) fornecem o padrão em meso-escala da bifurcação do fluxo da AIA ocorrendo dentro da Bacia de Santos. Stramma \& England (1999), através de densa reanálise de dados hidrográficos, respaldados por simulacões de dois diferentes modelos numéricos de circulacão global, corroboram Müller et al. (1998), centrando o eixo da bifurcacão da AIA ao sul de $25^{\circ} \mathrm{S}$. Tal resultado foi confirmado pela compilação de dados de 170 flutuadores de diversos tipos realizada por Boebel et al. (1999). A bifurcação da AIA ocorreria à longitude de Santos, mas com o eixo da divergência ocorrendo praticamente paralelo ao talude em torno de $28^{\circ} \mathrm{S}$ (Fig. 5). O escoamento associado à AIA, denominada de Corrente de Contorno Oeste Intermediária pelos autores, fluiria praticamente para o norte no interior da Bacia de Santos.

Subjacente à AIA, a APAN é caracterizada por valores de temperatura entre $3^{\circ} \mathrm{C}-4^{\circ} \mathrm{C}$ e salinidades entre 34,6 - 35 ups, ocupando níveis entre $1500 \mathrm{~m} \mathrm{e}$ $3000 \mathrm{~m}$, ao largo do Sudeste brasileiro. Há consenso na literatura de que, a APAN se apresenta como um fluxo organizado fluindo para o sul ao longo do contorno oeste até cerca de $32^{\circ} \mathrm{S}$ (Fig. 6), onde pelo menos parte da corrente retorna em direção ao Equador (Reid, 1989; Weatherly, 1993).

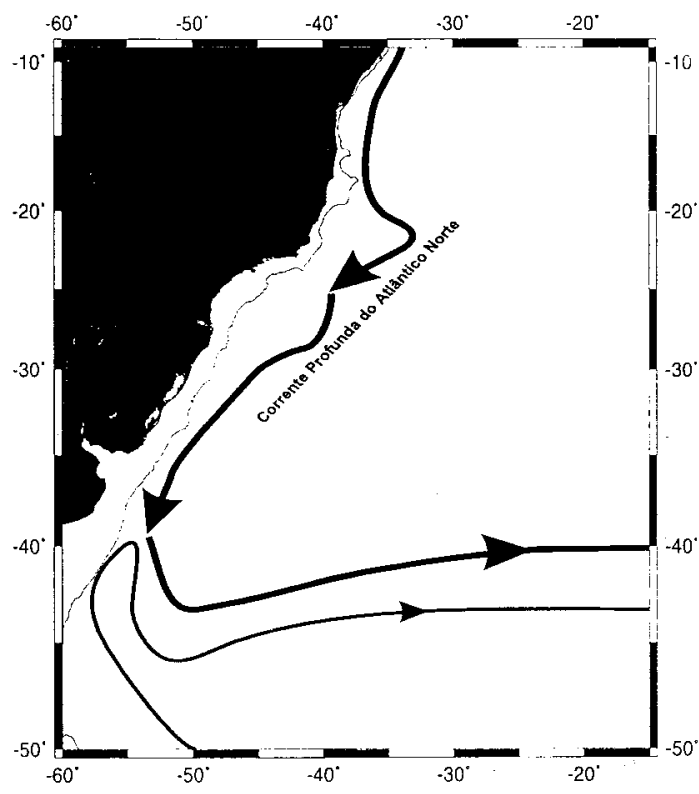

Fig. 6. Representação esquemática da circulação no Oceano Atlântico Sudoeste ao nível de $2000 \mathrm{~m}$. Baseada em Reid (1989) e Stramma \& England (1999).

A descrição acima das massas de água que compõem os três primeiros quilômetros de coluna d'água e seus padrões de escoamento no Atlântico Sul 
Subtropical levanta a discussão sobre $o$ que considerar como extensão vertical da $\mathbf{C B}$, ou em outras palavras, como definir esta corrente. Limitemo-nos aqui à elaboração de uma figura qualitativa, baseada nas informações apresentadas, deixando para a Seção 3 as estimativas de transporte de volume e detalhamentos da estrutura de velocidade da CB .

A figura que emerge é a seguinte. A poucos graus de latitude, ao sul de sua área de formação (região de bifurcação do ramo sul da CSE ), a CB é uma corrente rasa, quente e salina constituída basicamente por AT fluindo junto à quebra da plataforma. Nos entornos da latitude de $20^{\circ} \mathrm{S}$, onde recebe efetiva contribuição da ACAS, se torna mais profunda e cresce em transporte (Fig. 4). Em $28^{\circ} \mathrm{S}$, no sul da Bacia de Santos, a espessura da ACAS se estende até $750 \mathrm{~m}$ e a corrente apresenta-se organizada até esta profundidade (Evans \& Signorini, 1985; Campos et al., 1995).

Abaixo de $25^{\circ} \mathrm{S}, \mathbf{A T}$, ACAS, AIA e APAN fluem consonantemente na direção do polo Sul. Levanta-se então o dilema se consideramos o fluxo da AIA como parte da CB, o que significaria considerar uma corrente de contorno oeste com estrutura vertical de $3000 \mathrm{~m}$.

A escolha do que definir como CB pode seguir tanto critérios dinâmicos, como os cinemáticos, ou mesmo históricos. Um critério dinâmico seria utilizar o conceito teórico de que a CB é uma corrente de contorno oeste, requerida pelo transporte de Sverdrup para "fechar" a circulação gerada pelo vento no Giro Subtropical. Caso seguido, esse critério delimitaria como $\mathbf{C B}$ apenas o fluxo associado ao movimento da AT e ACAS. Essa definição da CB é adotada pela vasta maioria dos autores, provavelmente, por razões históricas, e será também adotada na presente revisão. Vale ressaltar que, no entanto, foi Wüst (1935) quem introduziu $\mathbf{C B}=\mathbf{A T}+\mathbf{A C A S}$ e este autor utilizou argumentos observacionais para formulá-la.

Foi Zemba (1991) quem considerou a CB com inclusão dos fluxos da AIA e APAN, partes integrantes da circulação termohalina. Seu argumento é cinemático, alegando que se a definição de corrente compreende todo o fluxo contíguo fluindo na mesma direção que a corrente em superficie, por que não considerar a inclusão dos fluxos da AIA e APAN como parte da CB ao sul de $25^{\circ} \mathrm{S}$ ? Certamente, a "fusão" entre a CB , definida classicamente, com a Corrente de Contorno Oeste Profunda acarretaria uma "nova" CB quase tão intensa (em termos de transporte) como a CG (Zemba \& McCartney, 1988)*. Por outro lado, tal definição colocaria a CB

(*) Zemba, J. C. \& McCartney, M. S. 1988. Transport of the Brazil Current: it's bigger than we thought. (Abstract). EOS; 69(44) : 1237. em classe distinta das demais correntes de contorno oeste subtropicais (CG , Kuroshio, Corrente das Agulhas e Corrente do Leste da Autrália), visto que não há coerência dos fluxos de superfície com os intermediários e profundos nos outros oceanos. Entretanto, a definição da CNB , corrente de contorno oeste que fecha o Giro Equatorial do Oceano Atlântico, inclui os fluxos por forçantes termohalinas da AIA , que nessas latitudes tropicais fluem em direção ao norte subjacentes à ACAS (Silveira et. al., 1994; Bub \& Brown, 1996). É claro que a dinâmica da CNB e da CB são distintas, apesar da origem comum. Mas, neste contexto, tal discussão acima tem o objetivo de exemplificar que a polêmica dos critérios de definição das feições da circulação oceânica está longe de ser uma questão fechada.

\section{Velocidade e transporte da Corrente do Brasil}

A maioria das estimativas de transporte calculado para CB tem se concentrado em duas regiões: próximo ao Rio de Janeiro e na Zona de Confluência Brasil-Malvinas. Como o objetivo desse manuscrito é rever o estado do conhecimento atual da Corrente do Brasil ao largo do Leste brasileiro, concentraremos nossa revisão até a latitude de $30^{\circ} \mathrm{S}$. A quase totalidade dos valores encontrados na literatura são provenientes de cálculo geostrófico. As perfilagens de velocidade, pelo instrumento PEGASUS, resumem-se à iniciativa pioneira descritas em Evans et al. (1983) e Evans \& Signorini (1985). Avaliação do transporte por medições correntométricas são únicas e referentes ao Experimento WOCE (Müller et al., 1998). O mais completo compêndio sobre valores de transporte da CB foi elaborado por Garfield (1990) e a Tabela 1 representa sua atualização.

Descrições da CB próxima à sua origem ficam praticamente restritas às análises geostróficas de Stramma et al. (1990). Esses autores, utilizando radiais hidrográficas históricas do "World Oceanographic Data Center-WODC", propõem que a origem da $\mathbf{C B}$ ocorre devido à bifurcação do ramo sul da CSE, que transporta $8 \mathrm{~Sv}\left(1 \mathrm{~Sv}=10^{6} \mathrm{~m}^{3} \mathrm{~s}^{-1}\right)$ nos primeiros $500 \mathrm{~m}$ de coluna d'água, em torno de $10^{\circ} \mathrm{S}$ (Fig. 7). A CB geostrófica então rumaria para o sul, transportando $4 \mathrm{~Sv}$ e fluindo sobre a quebra da plataforma.

Em $15^{\circ} \mathrm{S}$, devido ao alargamento da plataforma continental, a $\mathbf{C B}$ se afasta da costa, embora às vezes meandre em direcão à plataforma interna. Stramma et al. (1990) consideram a possibilidade de uma célula de (re)circulação ciclônica costeira que transporta $2 \mathrm{~Sv}$ (Fig. 7), entre $12^{\circ} \mathrm{S}$ e $16^{\circ} \mathrm{S}$. O resultado é o transporte da $\mathbf{C B}$ nessas latitudes estimado em $6 \mathrm{~Sv}$ (Tab. 1). 
Tabela 1. Estimativas de Transporte de Volume e Velocidade Máxima da Corrente do Brasil, entre $10^{\circ} \mathrm{S}$ e $31^{\circ} \mathrm{S}$. Adaptada de Garfield (1990).

\begin{tabular}{|c|c|c|c|c|}
\hline $\begin{array}{l}\text { Latitude } \\
\text { (S) }\end{array}$ & $\begin{array}{l}\text { Profundidade de } \\
\text { Referência } \\
\text { (m) }\end{array}$ & $\begin{array}{l}\text { Transporte de Volume } \\
\qquad\left(10^{6} \mathrm{~m}^{3} \mathrm{~s}^{-1}\right)\end{array}$ & $\begin{array}{l}\text { Velocidade Máxima } \\
\qquad\left(\mathrm{ms}^{-1}\right)\end{array}$ & Referência Bibliográfica \\
\hline $9^{\circ}-13^{\circ}$ & $390-510$ & 4,1 & 0,31 & Stramma et al. (1990) \\
\hline $15^{\circ}$ & $470-530$ & 6,0 & 0,16 & Stramma et al. (1990) \\
\hline $19^{\circ}$ & 500 & 6,5 & 0,72 & Miranda \& Castro (1981) \\
\hline $19^{\circ}$ & 500 & 5,3 & 0,50 & Evans et al. (1983) \\
\hline $19^{\circ} 25^{\prime}$ & $470-640$ & 5,7 & 0,19 & Stramma et al. (1990) \\
\hline $20^{\circ} 3^{\prime}$ & $590-630$ & 1,6 & 0,24 & Stramma et al. (1990) \\
\hline $20^{\circ} 28^{\prime}$ & $3,8 / 6,8$ & $500 / 1000$ & 0,52 & Evans et al. (1983) \\
\hline $21^{\circ} 40^{\prime}$ & 500 & 4,4 & 0,61 & Evans et al. (1983) \\
\hline $22^{\circ}$ & $500-1300$ & 5,2 & 0,19 & Signorini (1978) \\
\hline $23^{\circ}$ & $500-1300$ & 4,4 & 0,52 & Signorini (1978) \\
\hline $23^{\circ}$ & 550 & $2,2 / 2,7$ & 0,49 & Miranda \& Castro (1979) \\
\hline $23^{\circ}$ & Pegasus & 11 & 0,50 & Evans \& Signorini (1985) \\
\hline $23^{\circ}$ & Pegasus & 6 & 0,70 & Garfield (1990) \\
\hline $23^{\circ}$ & $600 / 1300$ & $10,1 / 10,9$ & - & Stramma (1989) \\
\hline $23^{\circ} 30^{\prime}$ & $500-1300$ & 8,0 & 0,75 & Signorini (1978) \\
\hline $24^{\circ}$ & 1300 & 7,5 & 0,25 & Fisher (1964) \\
\hline $24^{\circ}$ & $500-1300$ & 14,0 & 0,62 & Signorini (1978) \\
\hline $24^{\circ}$ & $500 / 1000$ & $4,1 / 7,8$ & 0,31 & Evans et al. (1983) \\
\hline $24^{\circ}$ & $600 / 1300$ & $9,4 / 10,1$ & - & Stramma (1989) \\
\hline $24^{\circ}$ & Correntômetro & 1,3 & - & Müller et al.(1998) \\
\hline $24^{\circ} 30^{\prime}$ & $500-1300$ & 13,2 & 0,68 & Signorini (1978) \\
\hline $25^{\circ}$ & 750 & 7,3 & 0,60 & Campos et al. (1995) \\
\hline $28^{\circ}$ & Correntômetro & 16 & - & Müller et al. (1998) \\
\hline $28^{\circ}-30^{\circ}$ & $1550-1600$ & 11,4 & 0,70 & Fisher (1964) \\
\hline $31^{\circ}$ & Pegasus & 18 & 0,80 & Garfield (1990) \\
\hline
\end{tabular}

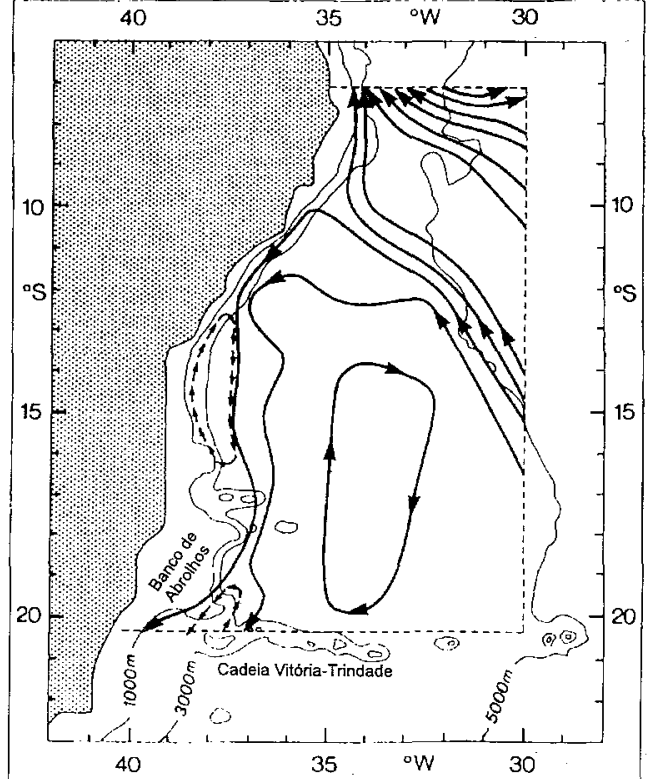

Fig. \% Kepresentação esquemática da região de origem da Corrente do Brasil, baseada em seções históricas do WODC. Cada linha sólida representa um transporte de 2 Sv. De acordo com Stramma et al. (1990).
Em $19^{\circ} \mathrm{S}$, a CB permanece como uma corrente estreita $(\approx 75 \mathrm{~km}$ de largura) e rasa. $O$ transporte (relativamente à superficie isanostérica de $130 \mathrm{cl} \mathrm{ton}^{-1}$, ou $\approx 500 \mathrm{~m}$ ) é de $5,5 \mathrm{~Sv}$ e velocidade de superfície máxima de $0,72 \mathrm{~ms}^{-1}$, sendo que mais de $50 \%$ encontra-se confinado aos primeiros $200 \mathrm{~m}$ (Miranda \& Castro, 1981).

Em $20,5^{\circ} \mathrm{S}$, a CB se depara com a Cordilheira Trindade-Vitória. Evans et al. (1983), através de dados batitermométricos e hidrográficos, mostraram que a corrente fluiu continuamente através da passagem mais próxima à costa (Fig. 8). Os transportes geostróficos obtidos eram de aproximadamente $4 \mathrm{~Sv}(8 \mathrm{~Sv})$, relativamente ao nivel de $500 \mathrm{db}(1000 \mathrm{db})$. Ao sul da cadeia, a CB mantinha-se confinada e organizada sobre o talude continental.

Próximo à Cabo Frio, em $23^{\circ} \mathrm{S}$, Signorini (1978) capturou uma CB meandrante em sua análise de topografia dinâmica. Na radial normal à Cabo Frio, estimou o transporte relativo à profundidade de $600 \mathrm{~m}$ como sendo de $9,4 \mathrm{~Sv}$, contido em dois ramos, com um pico de velocidade geostrófica de superficie da ordem de $0,55 \mathrm{~ms}^{-1}$ 
(Fig. 9). Semelhante à latitude de $19^{\circ} \mathrm{S}$, mais de $50 \%$ do transporte está concentrado em profundidades menores que $200 \mathrm{~m}$.

Miranda \& Castro (1979) também detectaram um padrão meandrante na $\mathbf{C B}$ em suas observacões hidrográficas na região adjacente à Cabo Frio, $\left(23^{\circ} \mathrm{S}\right)$, ao longo de duas seções meridionais. Estes autores encontraram como principal característica da circulação geostrófica (relativamente à superfície isanostérica de $110 \mathrm{cl}$ ton $^{-1}$, cerca de $550 \mathrm{~m}$ na região) a ocorrência de movimentos para oeste (no lado oceânico das seções) e leste (próximo à quebra de plataforma), sugerindo um cisalhamento ciclônico, com velocidades máximas de até $-0,49 \mathrm{~ms}^{-1}$ e $0,12 \mathrm{~ms}^{-1}$, respectivamente. $O$ movimento para leste apresentava um transporte de volume de $0,52 \mathrm{~Sv}$ e $0,40 \mathrm{~Sv}$ nas duas seções. O movimento para oeste apresentava valores de transporte de volume de $-2,24$ Sv e $-2,68$ Sv. A análise do diagrama T-S volumétrico, conduzida pelos autores, mostra que o escoamento limitado aos primeiros $500 \mathrm{~m}$ de profundidade concerne às AT e ACAS .

Signorini et al. (1989) calcularam a corrente geostrófice para dados hidrográficos e batitermométricos na região de Cabo Frio, em relação à superficie isobárica de $500 \mathrm{db}$. Os pesquisadores encontraram uma boa concordância na região próxima ao talude, onde flui a $\mathbf{C B}$ com velocidades máximas na superficie, próximas a 0,3 $0,4 \mathrm{~ms}^{-1}$, e transporte de volume resultante de aproximadamente $3,3 \mathrm{~Sv}$.
As observações, até agora singulares, com o perfilador PEGASUS (Evans \& Signorini, 1985) nesta latitude, revelaram valores da ordem de $6 \mathrm{~Sv}$ para o fluxo acima da AIA. As velocidades na direção sudoeste atingem mais de $0,5 \mathrm{~ms}^{-1}$. As medições diretas de velocidade confirmam as geostróficas, mostrando uma CB rasa. A inversão de velocidade se dá em $400 \mathrm{~m}$, onde aparece o fluxo para nordeste devido à AIA (Fig. 10). Evans \& Signorini (1985) mencionam, ainda, que cerca de outros $6 \mathrm{~Sv}$ fluem consonantemente à CB, em regiões interiores à quebra da plataforma.

Medições recentes, realizadas como parte do WOCE, forneceram estimativas de transporte para a CB dentro da Bacia de Santos. Campos et al. (1995) utilizaram dados hidrográficos com alta resolução horizontal e estimaram o transporte da CB em $7,5 \mathrm{~Sv}(8,8 \mathrm{~Sv})$ relativamente ao nível de $750 \mathrm{db}(900 \mathrm{db})$. A CB dentro da Bacia de Santos se estende em média até $750 \mathrm{~m}$, o limite estimado pelos autores entre ACAS e AIA.

As análises dos dados correntométricos dos fundeios do WOCE por Müller et al. (1998), entre $20^{\circ} \mathrm{S}$ e $28^{\circ} \mathrm{S}$, confirmam estimativas pretéritas que a CB se torna mais profunda e com maior transporte em direção ao sul. A CB tem profundidade em torno de $200 \mathrm{~m}$ no fundeio ao largo de Cabo Frio e com velocidades médias da ordem de $0,15 \mathrm{~m} \mathrm{~s}^{-1}$. Em $28^{\circ} \mathrm{S}$, nas proximidades do Cabo de Santa Marta Grande, sua profundidade ultrapassa os $670 \mathrm{~m}$ e velocidade média em torno de $0,5 \mathrm{~m} \mathrm{~s}^{-1}$. O transporte da $\mathbf{C B}$ nessa latitude é cerca de $16 \mathrm{~Sv}$.

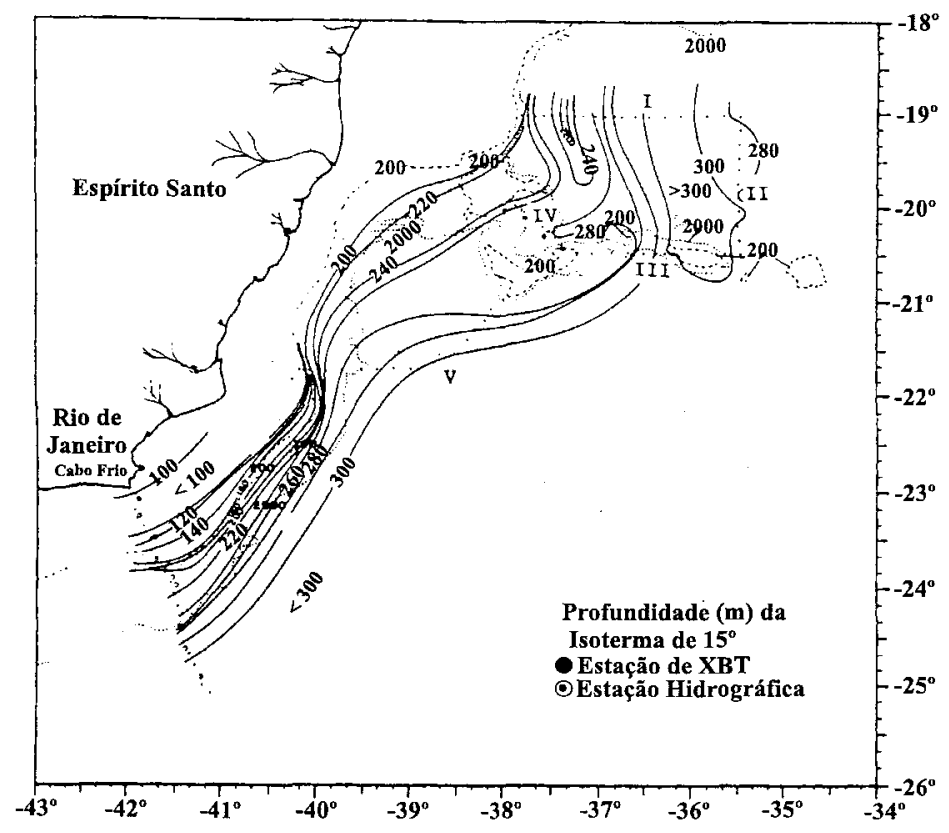

Fig. 8. Profundidade da isoterma de $15^{\circ} \mathrm{C}$ na região da Cadeia Vitória-Trindade em abril de 1983. A região de gradiente indica a presença da frente da Corrente do Brasil. De acordo com Evans et al. (1983). 


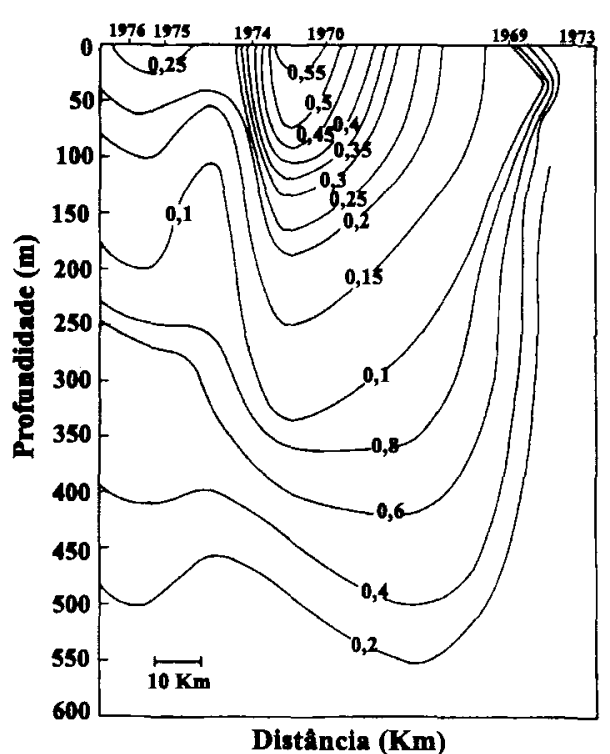

Fig. 9. Seção de velocidades geostróficas (relativas a 600 db) em radial normal ao Cabo Frio $\left(\approx 23^{\circ} \mathrm{S}\right)$. De acordo com Signorini (1978).
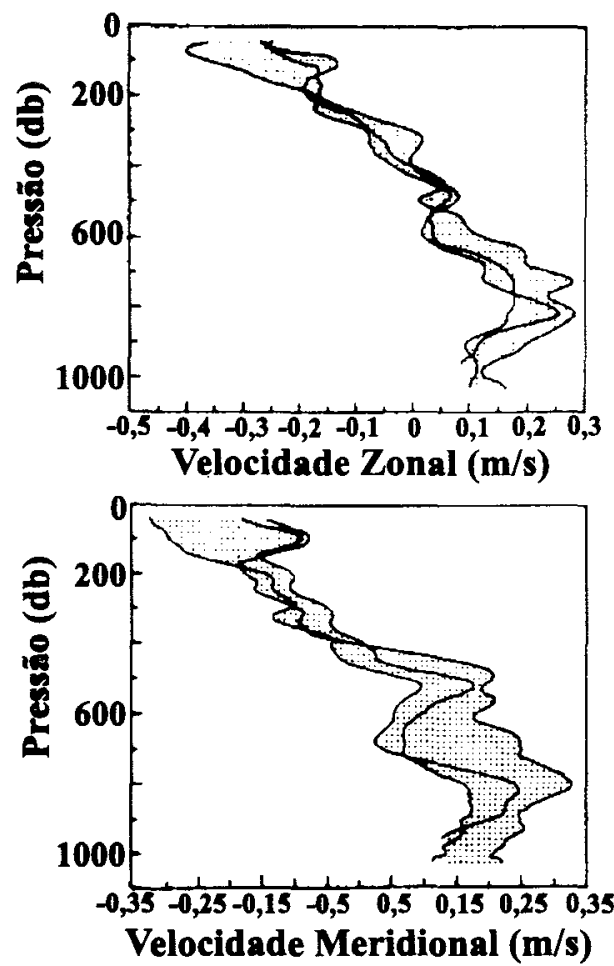

Fig. 10. Componentes observadas zonal (painel superior) e meridional (inferior) em três lançamentos do perfilador PEGASUS ao largo de Cabo Frio, ao longo de uma semana. De acordo com Evans \& Signorini (1985).

Gordon \& Greengrove (1986) investigaram a zona de Confluência Brasil-Malvinas, encontrando um transporte da CB em $38^{\circ} \mathrm{S}$ de 19 Sv na direção sul, relativo a profundidade de $1400 \mathrm{~m}$. O valor deste transporte representa um aumento de aproximadamente $12 \mathrm{~Sv}$ em relação ao transporte encontrado sm $20^{\circ} \mathrm{S}$. Assim, estes autores estimaram a taxa de crescimento da $\mathbf{C B}$ em $5 \%$ à cada $100 \mathrm{~km}$. Esta taxa é comparável à da $\mathbf{C G}$.

\section{Meandros e vórtices da Corrente do Brasil}

A primeira descrição do meandramento da CB e os vórtices associados na região Sudeste foi realizada por Mascarenhas et al. (1971). Os autores descreveram a presença de estruturas vorticais, tanto ciclônicas como anticiclônicas, na região ao largo de Cabo Frio, a partir de mapas de topografia dinâmica. Em algumas das distribuições desta quantidade apresentadas nota-se um padrão tal como o de uma onda de vorticidade, com a presença de anticiclones sucedendo ciclones. Os autores comentam que parte deste meandramento atinge regiões interiores à plataforma continental. Mascarenhas et al. (1971), tanbém, especulam que feições topográficas da regiăo favoreceriam o meandramento e geração de vórtices pela $\mathbf{C B}$ nesta região.

Signorini (1978) retoma o tema do meandramento da $\mathbf{C B}$, discutindo a circulação entre o Cabo de São Tomé e a Baía de Guanabara. Este autor capturou um vórtice anticlônico em sua análise dinâmica de dados hidrográficos, ligeiramente ao norte de Cabo Frio (Fig. 11). O vórtice, com cerca de $100 \mathrm{~km}$ de raio, localizava-se em água profunda $(>1000 \mathrm{~m}$ ) com extensão vertical de aproximadamente $500 \mathrm{~m}$.

Campos (1995) discute os aspectos dinámicos que causariam o meandramento da CB. Este autor atribui a ocorrência de meandros e vórtices à mudança de orientação da costa e ao gradiente da topografia de fundo (plataforma estreita e abrupta ao norte de Cabo Frio, mais extensa e suave na Bacia de Santos). Segundo o autor, pode-se esperar que a CB, fluindo ao longo da quebra de plataforma, dirija-se por inércia às águas mais profundas na latitude de Cabo Frio, devido à mudança de direção da linha de costa. Por argumentos de conservação de vorticidade, espera-se que a CB meandre ciclonicamente e se comporte como uma onda de Rossby topográfica dentro da Bacia de Santos.

Evidências de meandros ciclônicos e ariticiclônicos, ao norte de Cabo Frio, já foram, também, detectadas por imagens de satélites (Fig. 12), sugerindo que o inicio da atividade vortical pode ser ao largo do Cabo de São Tomé $\left(22^{\circ} \mathrm{S}\right)$ por razões dinâmicas similares àquelas de Cabo Frio. $\mathrm{Na}$ Figura 12 observa-se um meandro ciclônico de grande amplitude em frente ao Cabo de São Tomé. Meandros anticiclônicos e ciclônicos se sucedem em direção à Bacia de Santos. 


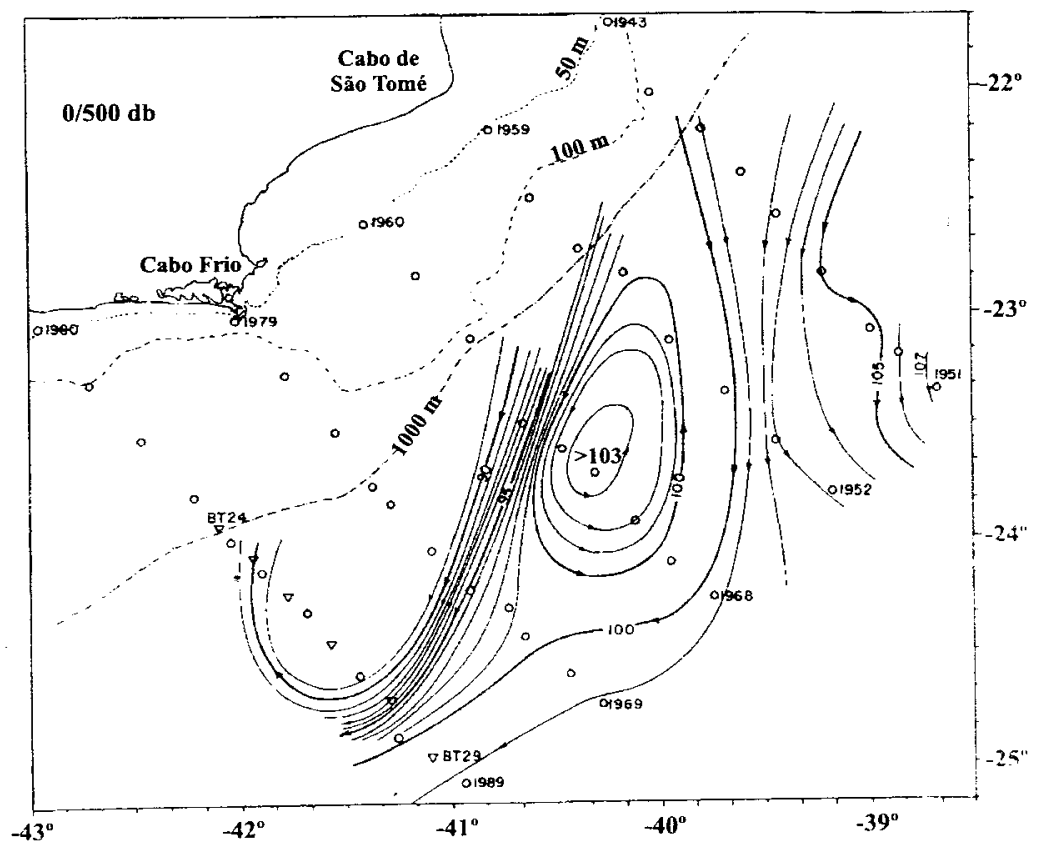

Fig. 11. Topografia dinâmica (em cm dinâmicos) relativamente a $500 \mathrm{db}$. De acordo com Signorini (1978).

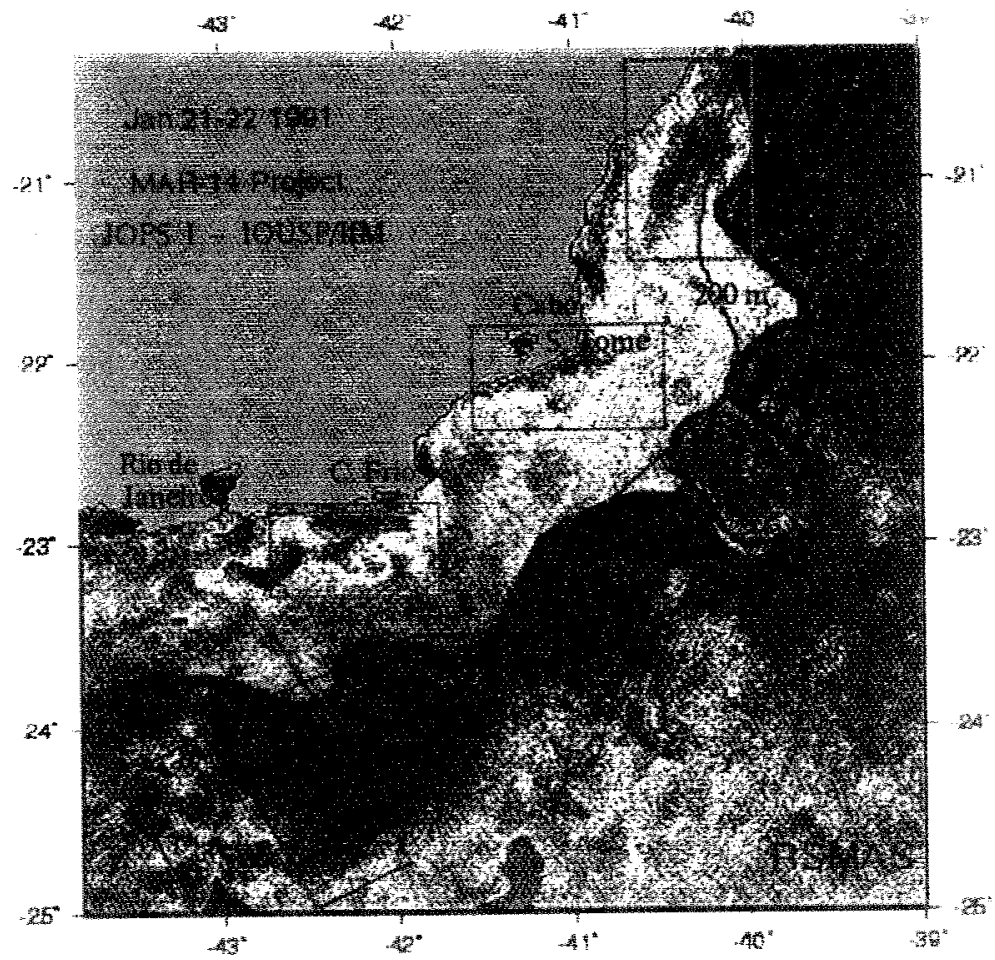

Fig. 12. Imagem AVHRR da costa Sudeste brasileira exibindo os meandros da Corrente do Brasil (tons avermelhados). A linha sólida vermelha foi editada para realçar o padrão meandrante. De acordo com Campos (1995).

Mais ao sul, na Bacia de Santos, ocorre a formação de pares vorticais, tanto de ciclones como de anticiclones, em lados opostos ao eixo da corrente, como mostrado na Figura 13. Essas estruturas são menores em tamanho que as de Cabo Frio, e aparentemente não se desprendem do eixo principal da CB (Garfield, 1990; Campos et al.,
1995; Campos et al., 1996). Os eventos de formação de vórtices, ao norte e dentro da Bacia de Santos, estão certamente relacionados, embora não exista relato na literatura. Informaçōes sobre a propagação dos meandros formados ao norte restringem-se aos esforços de modelagem (Velhote, 1998), e não de observações. 
A simples configuração espacial dos pares de vórtices na Bacia de Santos, seja por mapeamento usando dados quase-sinóticos (Campos et al., 1995) ou por imagens de satélites (Campos et al., 1996), nos conduz a uma comparação com fenômenos similares do hemisfério norte, como aqueles na Corrente da Flórida e os aneurismas quentes ("warm outbreaks") da CG. Para esse último fenômeno, Pratt et al. (1991), usando um modelo idealizado de vorticidade potencial, mostraram que tal estrutura seria consequiência de instabilidade barotrópica em ondas de vorticidade (tipo Rossby). Especulamos, aqui, que o fenômeno registrado pela Figura 13 seja ondas de Rossby topográficas barotropicamente instáveis.
Campos et al. (1995) dedicam no entanto especial atenção às estruturas vorticais ciclônicas. Estes autores propõem que ciclones da CB induzem "ressurgência de quebra de plataforma", trazendo ACAS para regiões da plataforma da Bacia de Santos. Em outras palavras, estas estruturas contribuiriam para a penetração da ACAS em regiões rasas, tal como a ressurgência induzida pelos ventos de Nordeste (via Transporte de Ekman), a qual é comum nos meses de verão (e que pode ser notada pelas águas de coloração verde na imagem da Figura 12). As implicações da penetração da ACAS são óbvias para a produtividade local: representa importante mecanismo que provê nutrientes às águas pobres sobre a plataforma (Fig. 14).
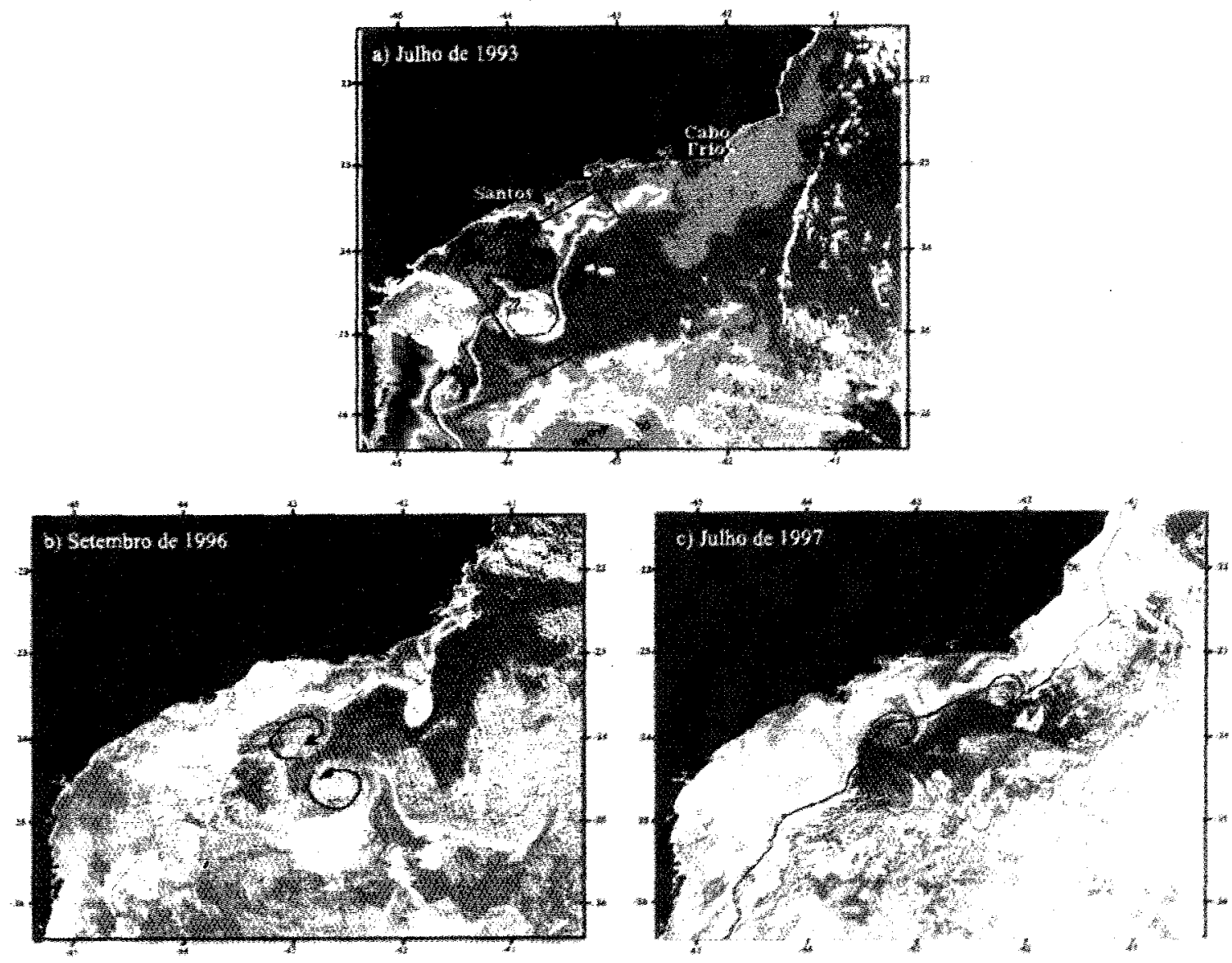

Fig. 13. Imagens AVHRR da região Sudeste do Brasil: (a) juiho de 1993; (b) setembro de 1996; (c) julho de 1997. As águas quentes (tons vermelhos) são características da Corrente do Brasil e as ondulações configuram meandros (editados com o sentido de rotação). Note no painel inferior a presença de uma estrutura vortical bipolar. De acordo com Velhote (1998). 


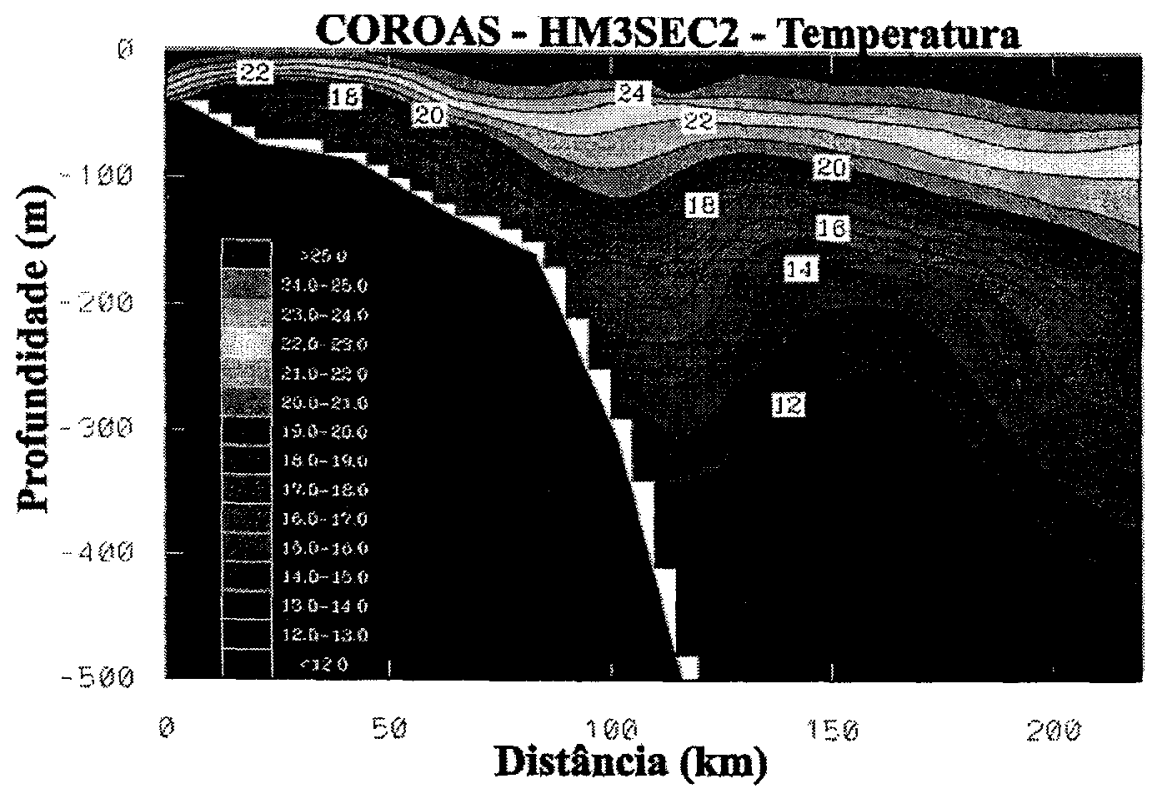

Fig. 14. Seção de temperatura ao largo da Itha de São Sebastião do Projeto COROAS (WOCE-Brasil) durante o verão de 1994. As inflexões nas isotermas indicam a presença de meandro ciclônico.De acordo com Campos (1995).

Campos et al. (2000) seguem os argumentos de Osgood et al. (1987) para explicar como se daria a contribuição da CB na ressurgência ao largo do Sudeste brasileiro. Explicam que o vórtice (ou meandro, visto que não há separação da estrutura do eixo da corrente) ciclônico tem núcleo de água fria e se propaga para sudoeste, com a CB (Fig.
15). A água em seu núcleo é continuamente renovada, devido à ressurgência na parte dianteira $e$ subsidência na parte traseira. Devido à sua circulação no sentido horário, o meandro "empurraria" a água ressurgida em sua parte dianteira para regiões rasas (como na Figura 14, em que águas de temperaturas inferiores a $18^{\circ} \mathrm{C}$ oalgam a quebra de plataforma).

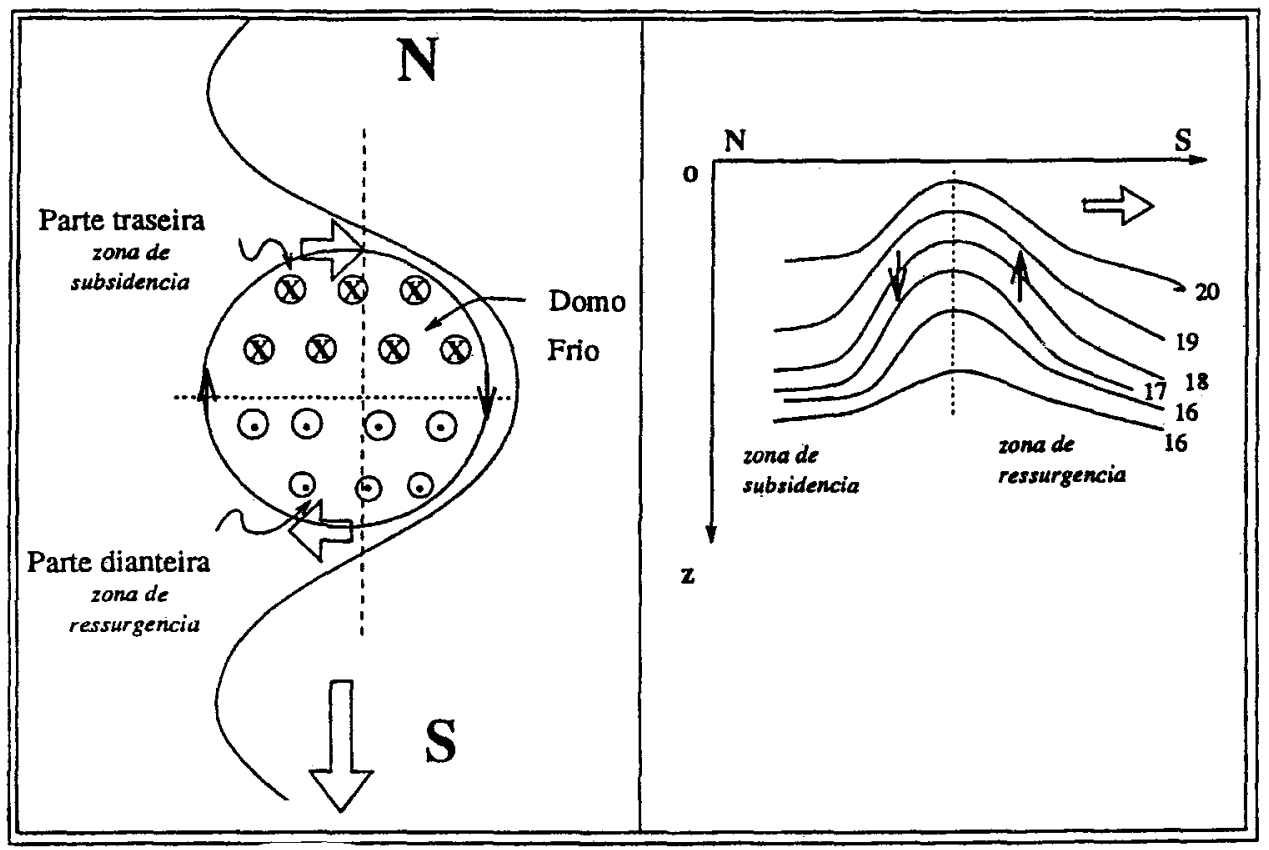

Fig. 15. Representação esquemática da ressurgência de quebra da plataforma induzida por meandro ciclônico. Painel esquerdo: vista horizontal. Painel direito: corte transversal em sua estrutura térmica. De acordo com Campos (1995). 
O mecanismo descrito por Campos et al. (2000) auxiliaria à ressurgência induzida pelo vento com disponibilização da ACAS em profundidades de quebra da plataforma. Se comprovado relevante, este mecanismo pode até mesmo tornar os eventos de penetração da ACAS sobre regiões da plataforma continental independentes da estação do ano, e não restrita ao verão austral. A avaliação do papel dos meandros ciclônicos também depende do conhecimento da freqüência de formação dos mesmos e suas velocidades de propagação, informações ainda não disponíveis na literatura.

\section{Agradecimentos}

Os autores gostariam de agradecer ao Prof. Dr. Belmiro Mendes de Castro Filho (IOUSP) pela sugestão da concepção desse artigo, ao Prof. Dr. Luiz Bruner de Miranda (IOUSP) pela atenciosa revisão e preciosas sugestões e aos dois revisores anônimos que muito contribuíram para a qualidade do manuscrito. Este artigo foi desenvolvido como parte do Projeto DINBRAS (Proc. 98/00572-2 - FAPESP) e Projeto DEPROAS (MCT/PRONEX).

\section{Referências bibliográficas}

Boebel, O.; Schmid, C. \& Zenk, W. 1997. Flow and recirculation of Antarctic Intermediate Water across the Rio Grande Rise. J. Geophys. Res., 102(C9):20967-20986.

Boebel, O.; Davis, R. E.; Ollitraut, M.; Peterson, R. G.: Richard, P. L.; Schmid, C. \& Zenk, W. 1999. The intermediate depth circulation of the Western South Atlantic. Geophys. Res. Let., 26(21):3329-3332.

Bub, F. L. \& Brown, W. S. 1966. Intermediate layer water masses in the Western Tropical Atlantic Ocean, J. Geophys. Res., 101(C5):11903-11922.

Buscaglia, J. L. 1971. On the circulation of the intermediate waters in the Southwestern Atlantic Ocean. J. Mar. Res., 29(3):245-255.

Campos, E. J. D.; Gonçalves, J. E. \& Ikeda, Y. 1995 Water mass structure and geostrophic circulation in the South Brazil Bight -- Summer of 1991. J. Geophys. Res., 100(C9):18537-18550.

Campos, E. J. D. 1995. Estudos da circulação oceânica no Atlântico tropical e região oeste do Atlântico Subtropical Sul. Tese de livre docência. Universidade de São Paulo, Instituto Oceanográfico. 114p.
Campos, E. J. D.; Ikeda, Y.; Castro, B. M.; Gaeta, S. A.; Lorenzetti, J. A. \& Stevenson, M. R. 1996. Experiment studies circulation in Western South Atlantic. EOS, 77(27):253-259.

Campos, E. J. D.; Velhote, D. \& Silveira, I. C. A. 2000. Shelf break upwelling driven by Brazil Current cyclonic meanders. Geophys. Res. Let., $27(6): 751-754$.

Defant, A. 1941. Die absolute topographie das phys. Meeresniveaus un der Druckflächen, sowie die Wasserbewegungen im Atl. Ozean. Meteor Werk., 6(2):191-250.

Emílson, 1. 1961. The shelf and coastal waters off Southern Brazil. Bolm Inst. oceanogr., S Paulo, 17(2):101-112.

Evans, D. L.; Signorini, S. R. \& Miranda, L. B. 1983. A note on the transport of the Brazil Current. J. Phys. Oceanogr., 13(9):1732-1738.

Evans, D. L. \& Signorini, S. R. 1985. Vertical structure of the Brazil Current. Nature, 315(6014):48-50.

Fisher, A. 1964. The circulation and stratification of the Brazil Current. Dissertação de mestrado. New York University. 86p.

Garfield III, N. 1990. The Brazil Current at subtropical latitudes. Tese de doutorado. University of Rhode Island. $121 \mathrm{p}$.

Gordon, A. L. \& Greengrove, C. H. 1986. Geostrophic circulation of the Brazil-Falkland confluence. Deep-Sea Res., 33(5) :573-585.

Mascarenhas Jr., A. S.;. Miranda, L. B. \& Rock , N. J. 1971. A study of oceanographic conditions in the region of Cabo Frio. In Costlow, J. D., ed. Fertility of the sea, New York, Gordon and Breach, 1:285-308.

Miranda, L. B. de 1985. Forma de correlação T-S de massa de água das regiões costeira e oceânica entre o Cabo de São Tomé (RJ) e a Ilha de São Sebastião (SP), Brasil. Bolm Inst. oceanogr., S Paulo, 33(2):105-119.

Miranda, L. B. de \& Castro Filho, B. M. 1979. Condições do movimento geostrófico das águas adjacentes a Cabo Frio (RJ). Bolm. Inst. oceanogr., S Paulo, 28(2):79-93.

Miranda, L. B. de \& Castro Filho, B. M. 1981. Geostrophic flow conditions of the Brazil Current at $19^{\circ} \mathrm{S}$. Ciencia Interamericana, 22(1-2): 44-48. 
Moreira, J. R. G. B. 1997. Correntes na plataforma externa e talude ao largo de Santos: observações no verão 1993. Dissertação de mestrado. Universidade de São Paulo, Instituto Oceanográfico. $214 \mathrm{p}$.

Müller, T. J.; Ikeda, Y.; Zangenberg, N. \& Nonato, L. V. 1998. Direct measurements of the western boundary currents between $20^{\circ} \mathrm{S}$ and $28^{\circ} \mathrm{S}, \mathrm{J}$. Geophys. Res., 103(C3):5429-543.

Osgood, K. E.; Bane, J. M. \& Dewar, W. K. 1987. Vertical velocities and dynamical balances in the Gulf Stream meanders, J. Geophys. Res., 92(C12):13029-13040.

Peterson, R. G. \& Stramma, L. 1991. Upper-level circulation in the South Atlantic Ocean. Progr Oceanogr., 26(1):1-73.

Piola, A. R. \& Gordon, A. L. 1989. Intermediate waters in the Southwest South Atlantic. Deep-Sea Res., 36(1):1-16.

Pratt, L. J.; Earles, J.; Cornillon, P. \& Cayula, J. F. 1991. The nonlinear behavior of varicose disturbances in a simple model of the Gulf Stream. Deep-Sea Res. I, 38: S591-S622.

Reid, J. L. 1989. On the total geostrophic circulation of the South Atlantic Ocean: Flow patterns, tracers, and transports. Prog. Oceanog., 23:149244.

Reid, J. L.; Nowlin, W. D. \& Patzert, W. P. 1977. On the characteristics and circulation of the Southwestern Atlantic Ocean. J. Phys. Oceanogr., 7:62-91.

Signorini, S. R. 1978. On the circulation and the volume transport of the Brazil Current between the Cape of São Tomé and Guanabara Bay. DeepSea Res., 25:481-490.

Signorini, S. R.; Miranda, L. B. de; Evans, D. L.; Stevenson, M. R. \& Inostroza, H. M. V. 1989. Corrente do Brasil: estrutura térmica entre $19^{\circ} \mathrm{e}$ $25^{\circ} \mathrm{S}$ e circulação geostrófica. Bolm Inst. oceanogr., S Paulo, 37(1):33-49.

Silveira, I. C. A. da; Miranda, L. B. de \& Brown, W. S. 1994. On the origins of the North Brazil Current. J .Geophys. Res., 99(C11):2250122512.

Stommel, H. 1965. The Gulf Stream: a physical and dynamical description. Berkeley, University of California Press. 248p.
Stramma, L. 1991. Geostrophic transport of the South Equatorial Current in the Atlantic, J. Mar. Res., 49(2):281-294.

Stramma, L. \& England, M. 1999. On the water masses and mean circulation of the South Atlantic Ocean. J. Geophys. Res., 104(C9): 20863-20883.

Stramma, L. 1989. The Brazil Current transport south of $23^{\circ} \mathrm{S}$. Deep-Sea Res., 36(4A):639-646.

Stramma, L.; Ikeda, Y. \& Peterson, R. G. 1990. Geostrophic transport in the Brazil Current region. Deep-Sea. Res., 37(1A): 1875-1886.

Suga, T. \& Talley, L. D. 1995. Antarctic intermediate water circulation in the tropical and subtropical Atlantic. J. Geophys. Res., 100(C7):13441-13453.

Sverdrup, H. U.; Johnson, M. W. \& Fleming, R. H. 1942. The Oceans: their physics, chemistry and general biology. Englewood Cliffs, Prentice-Hall Inc. $1087 \mathrm{p}$.

Taft, B. A. 1963. Distribution of salinity and dissolved oxygen on surfaces of uniform potential specific volume in the South Atlantic, South Pacific and Indian Oceans. J. Mar. Res., 21(2):129-146.

Tsuchya, M. 1986. Thermostads and circulation in the upper layer of the Atlantic Ocean. Prog. Oceanogr., 16:235-267.

Velhote, D. 1998. Modelagem numérica da ressurgência da quebra de plataforma induzida por vórtices ciclônicos da Corrente do Brasil na Bacia de Santos. Dissertação de mestrado. Universidade de São Paulo, Instituto Oceanográfico. $134 \mathrm{p}$.

Weatherly, G. L. 1993. On deep-current and hydrographic observations from a mudwave region and elsewhere in the Argentine basin. Deep-Sea Res. II, 40(4/5):939-961.

Wüst, G. 1935. Schichtung und zirukation des Atlantischen Ozeans. Die stratosphare des Atlantischen Ozeans. Wiss Ergebn. Deutsch. Atlant. Exp. "Meteor", 6:109-228.

Zemba, J. C. 1991. The structure and transport of the Brazil Current between $27^{\circ}$ and $36^{\circ}$ South. Tese de doutorado, Massachusetts Institute of Technology and Woods Hole Oceanographic Institution. 160p.

(Manuscrito recebido 07 outubro 1999; revisado 21 fevereiro 2000; aceito 10 novembro 2000) 